\title{
The Evolutionary Characteristics and Trends of China's Insurance Industry
}

\author{
Xiaolin Li \\ School of Insurance, Central University of Finance and Economics, Beijing 100081, China
}

中国保险业发展演化特征与趋势

李晓林

中央财经大学保险学院, 北京 100081 , 中国

\begin{abstract}
The role of mutual aid mechanisms of promoting economic growth and safeguarding social stability in China's insurance services industry has not received sufficient attention. Insurance development and innovation still lags behind the level of its economic development. It is difficult to cope with the impact of global intelligent technology innovation of financial insurance and uncertainty of international economy and finance. It is still far away from the production and good life needs of the motherland and the people. Accurately grasp the characteristics and trends of the development and evolution of the insurance industry under the banking and insurance merger supervision mode, promote the micro-insurance risk management and insurance technology innovation, organizational system innovation and cultural awareness innovation, and enhance the comprehensive strength to adapt to the
\end{abstract}

Sponsors:This study was supported by the major base projects of Ministry of Education, China: Research on the Mechanism and Intelligent Path of the Health Insurance System of Commercial Insurance Service in the Data Age（教 育部基地重大项目 “数据时代商业保险服务健康保障体系 的机制与智能路径研究” (16JJD790062). I am grateful to reviewers and editors for their insightful comments on this article.

Authors: X.L. Li, School of Insurance, Central University of Finance and Economics, Beijing100081, China.

Address: 39 South College Road, Haidian District, Beijing, China100081.Email: lixl@cufe.edu.cn trend of insurance internationalization. It also strengthens the supervision department to prevent innovation risks, protect and stimulate innovation, form new business development space and new profit growth points, achieve breakthroughs in the industrial value chain, promote growth industry path optimization and competitiveness improvement, strengthen national industrial safety, and adhere to the nature insurance of mutual aid. It has important reference value for safeguarding the essence and comprehensively improving the development of China's insurance service industry.

Keywords: characteristics and trends of industrial development; bank insurance merger supervision mode; China insurance industry

\section{摘要}

中国保险服务业互助共济的保障机制在促进经济增 长和保障社会稳定的作用并未受到足够重视, 保险发 展创新还严重滞后于经济发展水平, 难以应对全球智 能金融保险技术创新和国际经济金融不确定性的冲 击, 与经济社会发展和人民美好生活需要的距离还很 远, 发展面临巨大挑战。准确把握银保合并监管下保 险业发展演化的特征与趋势, 促进微观保险主体风险 管理与保险的技术创新、组织制度创新和文化意识创 新, 坚守保险保障本质, 以创新推动产业价值链的突 破, 形成新的业务发展空间和新的利润增长点, 推动 产业增长路径优化和竞争力跃升, 在适应保险国际化 趋势中提升产业综合实力, 同时, 强化偿付能力监管 
和防范创新风险, 中国保险服务业可以实现新的突破 和全面升级。

关键词: 产业发展特征与趋势; 银行保险合并监管; 中国保险业

\section{1. 引言}

保险是金融体系的重要产业之一, 不仅是社会经 济发展和人民生活中具有准公共品性质的基础设施, 而且在社会经济体系的消费、投资和进出口的稳定与 发展中发挥着 “助推器” 作用, 还在社会经济系统的 和谐运转中起着不可缺少的 “稳定器” 作用。目前, 我国正处在 “经济转轨” 与 “社会转型” 的重要战略 转变期, 以技术创新和经济发展为特征的 “全球合作 共赢”、“创业创新”、“精准扶贫” 和 “乡村振兴” 等 已成为我国经济社会发展的重要动力和新常态。

但是, 保险与社会生产和人民美好生活需要的距 离还很远, 互助共济机理与保障机制在促进经济增长 和保障社会稳定的作用与地位并未受到足够重视, 保 险业发展创新还严重滞后于经济发展水平, 难以应对 全球智能金融保险技术创新和国际经济金融不确定 性的冲击, 促进经济增长与稳定社会发展的作用有限。 因此, “加快发展现代保险服务业, 为经济转轨和社 会转型的国家发展战略服务” (保险业 “新国十条”, 2014），以及 “深化金融体制改革，增强金融服务实 体经济能力” (党的十九大报告, 2017) 成为必然选 择。显然, 现代保险服务业应当成为促进经济健康持 续发展, 保障社会安定团结, 满足人民日益增长的美 好生活需要的重要工具。从国家产业战略安全角度考 虑, 坚守保险保障本质, 全面审视银保合并监管模式 下保险业发展演化的特征与趋势, 在银保合并监管下 探讨中国现代保险服务业的健康发展之路是很有意 义的。

\section{2. 文献综述}

风险是保险存在的基础前提, 却不是保险产生的 直接动力。只有社会经济文化发展到一定程度, 物质 财富的丰富也达到一定水平, 人类社会才有了互助共 济模式的保险萌芽, 社会分工才逐渐细化, 保险精算 技术出现与法律体系完善, 才有了商业保险活动, 进 而才慢慢有了保险业的形成、发展和成熟（刘茂山, $1987^{[1]}$ ) 。因此, 保险业是保险商品经济活动发展 到一定阶段的产物, 是资本、劳动、知识等生产要素 和非生产要素资源逐渐从其它行业部门中分离出来, 以风险处理为中心, 专职分散风险, 提供保障功能的 一种特殊行业 (林宝清, $1993^{[2]}$, 刘茂山 ${ }^{[3]}, 2000$ )。
保险发展是制度环境的产物 (Skipper, $1992^{[4]}$; Robert W. Klein, $1995^{[5]}$ ) 。转型期中国保险业的 形成发展路径与保险制度和法律体系的建立和完善 关系极为紧密, 是中国保险市场发展现实与历史结合 的必然选择。

目前, 保险增长与发展不协调的根源是保险结构 不良, 而现象与根源却都是制度演化适应与市场博亦 的结果 (郑功成, $2015^{[6]}$; 宋平凡等, $2017^{[7]}$ )。在 现有银行保险混和监管制度文化环境路径下, 总结保 险业的发展特征与演化趋势, 抓好保险产业结构优化, 对于实现保险增长与发展同步和保险功能有效发挥, 积极推动保险服务于经济转轨与社会转型的国家战 略至为关键 (王绪瑾, $2017^{[8]}$; 张忠平等, $2017^{[9]}$ )。

\section{3. 中国保险业发展演化特征}

\section{1. 全球创新冲击巨大, 保障本质凸现}

随着世界经济金融化和金融自由化进程的加快, 以及计算机网络与卫星通讯技术的广泛应用, 互联网 (internet) 结合保险 (insurance) 结合创新 (innovation) 刺激了智能金融保险技术的创新步伐, 加快了金融保险的替代性融合, 推动了金融保险资源 和金融保险产业资源的全球性流动与市场整合, 加快 了世界保险业以结构优化升级为核心的保险资源争 夺和保险产业资源并购重组的一体化趋势。全球保险 业已进入了 “寡头主导, 大中小共生” 的垄断竞争格 局的快速发展时期, 一个保险资源和保险产业资源共 享的业务融合性统一的国际保险大市场正在逐渐形 成。保险资源和保险产业资源的跨国流动及其形成的 世界保险关系更加复杂, 保险资源和保险产业资源已 成为国际保险关系的焦点。竞争力弱势的发展中国家 的保险资源和保险产业资源不断流失, 不仅加剧了世 界保险发展与竞争态势的不平衡, 而且金融主权与金 融安全受到强烈冲击。这是世界保险业主动顺应一体 化趋势而以保险资源开发利用和保险产业资源重组 并购为核心所做出的战略性结构调整的反映, 也是金 融保险制度演化和市场博亦的产物。

中国保险资源丰富, 保险需求巨大, 经过近 40 年来的快速稳健市场化发展, 市场主体不断增多, 产 品越来越丰富, 已具备了良好的产业体系框架和初步 充满活力的市场结构。与之不匹配的是, 风险管理与 保险技术仍然比较落后, 保险组织制度与法律法规等 基础薄弱, 民众风险意识与保险意识普遍不高, 长期 非均衡的粗放发展模式, 还没法让巨大的市场需求充 分表现出来, 导致保险资源开发利用率较低, 保险产 业资源使用效率不高, 引起保险增长与发展相背离, 
造成保险发展与经济社会发展和人民美好生活需要 不相适应,与建立完善的社会主义市场经济体制不相 适应, 与全球经济金融自由化下的全面开放新形势和 构建社会主义和谐社会的要求不相适应, 在参与构建 完善的社会保障机制、合理的社会利益协调机制、有 效的社会矛盾疏导机制、科学的社会管理机制和完善 的社会预警机制等方面发挥的作用还不充分。而这正 是应着力的方向。目前, 我国正处在 “经济转轨” 与 “社会转型” 的重要战略转型期, 我国经济社会发展 迫切需要保险服务业的支持; 保险先是发挥其 “社会 稳定器” 的功效, 以其互助共济机理与保障机制服务 社会, 然后便有 “经济助推器” 的作用。

\section{2. 市场集中度偏高与产业绩效不高并存}

目前, 我国整个保险行业市场结构已逐渐与世界 保险市场一致, 即由高度垄断转变为群雄竞起的 “寡 头主导, 大中小共生”, 但是, 我国保险业由政府主 导市场化改革形成的寡头垄断市场结构不同于发达 市场化国家由市场自发形成的塞头垄断市场结构。依 然较高的市场集中度，降低了市场机制基础性的资源 配置作用, 阻碍了微观创新, 形成了企业间无效竞争, 也导致了整个产业绩效较差。

显然, 高市场集中率也难以换取高利润率, 两者 之间并不存在确定的相关关系, 既有来自转型中的市 场体制和政府规制，也有市场结构缺乏竞争性和市场 行为不规范等非效率市场竞争的结果。在现有制度模 式下, 希望单纯通过降低行业集中度和降低市场份额 的做法并不能从根本上提高企业绩效, 并不能抑制市 场结构不合理和市场行为不规范的态势, 难以使企业 真正以利润最大化作为经营管理目标。

事实上, 尽管费率市场化改革推动了保险市场集 中度的缓慢下降, 但是, 市场集中度的降低并未带来 行业绩效的同时改善, 行业绩效和市场集中度、垄断 程度之间没有展示出明显的相关关系。市场结构之外 的其他因素所决定了行业绩效, 企图想通过降低市场 集中度, 降低市场份额等办法来提高行业绩效, 常常 是难以实现的。而且, 在保险公司开设、产品创新审 批、保险企业兼并、破产法规和完善的市场退出保障 机制等方面有较为严格的法律法规和政策限制, 而在 企业规模和产品差别化方面则未形成明显管制和壁 垒, 才会出现尽管非寿险费率已经全面市场化了, 竞 争更加激烈, 大公司并没有因综合优势赢得高利润和 高绩效。相反, 在寿险的价格监管下, 大公司也未能 从产品创新中获取高额利润。整个寿险行业的盈利能 力低, 行业绩效呈现下降趋势, 个别公司甚至还出现 亏损, 行业规模的扩大是以利润率的降低为代价的。
而且, 尽管寿险市场集中度比较高, 大公司市场份额 很高, 利润率也不高。

\section{3. 居民收支预期缺口大, 有效需求不足}

随着经济的持续增长, 居民消费结构和水平逐渐 由生存主导型向发展享受型转化升级, 必然促进保险 需求增加。但是, 我国保险市场的有效需求长期呈现 相对不足的特征, 保险对社会经济发展和人们生活的 渗透和影响还不深。许多人逐渐有了一定的结余, 为 何在保险消费方面舍不得花钱呢?

其实, 当收入水平较低时, 需要转移风险的投保 人无力支付保费, 或者有能力支付保障成本的投保人 过少, 单位保单所负担的成本较高, 投保人就没有动 力利用保险商品来转移风险, 保险有效需求也就无法 形成。然而, 当人均收入水平达到某一临界值时, 有 能力支付保障成本的投保人较多, 较多的保单量使得 单位保险所负担的成本较低时, 投保人利用保险商品 来转移风险的经济基础具备了, 收入水平达到潜在保 险需求转化成现实有效需求的 “门槛” 值时 (国际上 通常认为 2000-3000 美元是保险需求的转折点), 保 险有效需求也就自然形成。较为贫困的, 虽然有风险 意识, 但买不起保险, 形成不成有效的保险需求。非 常富有的, 对保险商品的效用很低, 也形不成有效保 险需求, 即使消费了保险, 也是看好保险的避税功能 做的财富转移安排。因此, 收入位于中间区域的保险 需求的收入弹性较大, 两头两尾极端收入区域的弹性 较小。

尽管社会经济发展状况和人均收入水平是保险 安全服务消费有效需求产生的前提, 但是, 居民对未 来的预期也影响着保险安全服务消费有效需求的产 生。能否接受良好教育, 能否住得好点, 退休后是否 吃饭吃药有保障, 这些都会影响着人们的预期。随着 居民收入的持续增加, 除了金融资产有更多的选择外, 消费水平与结构应该有显著的提高, 由于风险意识和 消费偏好影响, 即使保险成本比预防性储蓄保障机制 要低廉, 但在风险保障的方式上仍然偏好银行存款等 储蓄性的保障方式, 而不是互助共济的保险保障模式, 保险产品在人们预防性资产中占比非常低, 人们对银 行体系仍然过渡依赖。在这样的社会消费心理下, 保 险有效需求生成途径的滞涩使保险消费成为人们生 活的组成部分还有很多障碍, 释放居民消费能力的保 险替代性挤出效应难以真正发挥, 难以形成有效的保 险需求, 保险并没有在金融体系与社会保障中发挥应 有的作用。 


\section{4. 区域保险差异较大, 非均衡发展突出}

区域保险是保险业的发展基础，区域保险的非均 衡发展既不利于微观保险经营风险的分散, 影响保险 市场结构、市场竞争和市场绩效，也不利于整个保险 业国际竞争力的提升, 更不利于保险业的可持续发展。 目前, 区域间产品业务供求结构单一, 相对缺乏与相 对过剩并存, 东西区域业务结构长期失衡。随着居民 收入增加, 全国和东部、中部以及民族地区的寿险消 费都在逐年增加, 即寿险消费与个人可支配收入呈正 相关。而且, 我国人口总抚养比一直呈下降趋势, 总 少儿抚养比逐年下降, 总老年抚养比逐年上升。民族 地区计生政策宽松下的年龄结构好于东部, 而且, 民 族地区与中部地区的家庭养老习俗重于社会化养老 为主的东部经济发达地区。因此, 东部地区的寿险消 费随着总抚养比的上升而上升, 中部地区和民族地区 则随着总抚养比的上升而下降, 西藏等地的人口年龄 结构年轻, 老龄化比例不高, 其需求结构出现了调整, 支出的时间模式也将后移, 因此, 西藏等地的寿险消 费将下降。东部地区的寿险消费与总抚养比呈正相关, 民族地区和中部地区寿险消费与总抚养比呈负相关。

其次, 东部地区市场化程度和经济发展水平均高 于民族地区, 市场机制在东部地区的资源配置中已发 挥明显作用, 利率上调将会降低寿险产品的相对价值, 导致寿险产品价格的升高, 从而抑制投保人的保险需 求, 造成寿险公司承保业务的萎缩。而民族地区市场 机制还不完善, 投融资制度也不健全, 贷款的使用效 率较低, 利率对其寿险消费影响为正相关关系。因此, 随着老年抚养比的提高, 居民对储蓄类的利率敏感型 寿险产品的需求增加, 寻求死亡保障的动机不足, 对 死亡类的寿险产品的需求减少, 反而投资动机和寻求 养老保障动机强烈。如果采用一统费率, 会造成东部 对民族地区保险资源的掠夺, 不利于民族地区的经济 发展。而且, 通胀对传统寿险的影响显著为负, 对投 资型寿险的影响显著为正, 通胀减少了对传统寿险的 需求, 提升了对投资型寿险的需求, 新型寿险较好地 抵御了保单的通胀风险, 加速了居民储蓄向包括寿险 保单在内的金融资产的转化。通胀对全国和东部地区 寿险消费影响显著为正, 对中部和民族地区传统寿险 消费的影响为负，对民族地区的传统寿险消费的负向 影响最小。

另外, 城乡业务分布极不均衡, 城市保险业务一 直占据保险市场业务量的绝大部分, 农村保险供求矛 盾非常突出, 保险支持精准扶贫的有效模式还需要进 一步探索。受保费规模指标和业务地域限制, 保险机 构无法下设到县一级, 经营触角也难以延伸到乡镇,
农村保险市场实际还是一个完全垄断的市场, 缺乏竞 争导致保险有效供给不足。而且, 保险大多数产品都 是针对城市居民设计的, 较少考虑到农民收入较低且 不稳定的特点, 产品保障的范围、缴费额和缴费期限 都超出了农民的承受水平, 不能满足县域农民的保障 需求, 更没有考虑到民族体质和区域地方性疾病等差 异。另外, 过于专业的保险条款不利于农民了解产品, 降低了投保热情, 导致县域保险发展长期滞后。

\section{5. 资产规模较小, 业务拓展受限}

我国保险市场准入管制依然严格, 资金进入渠道 受阻, 国有成份较重, 民营参股不多, 外资渗透较少, 资金来源并不充分, 股权结构不合理, 资金规模较小。 而且, 长期在国家信用支撑下从事保险经济活动, 经 营绩效和风险意识不强, 对资本规模与结构重视不够, 资本增长率低于快速的业务增长规模, 在承保利润下 降和投资收益不高的双重压力下, 要在短期内通过内 部积累转增资本来增大资本规模, 改善资本结构显然 力不从心。要借助民营资本不断向保险业渗透来改善 资本结构, 但其缺乏保险经营管理实际操作经验, 缺 乏信任, 短期内很难成为保险资本金来源的重要渠道。 因此, 保险公司的偿付能力明显不足, 与国际水平相 比资本充足率水平有较大的差距, 尽管新成立的公司 相对其业务 “吃不着与吃不饱” 的资本充足率较高, 但随着业务扩展, 其资金来源渠道障碍下的资本充足 率制约问题必然显现。在快速成长中不及时通过各种 渠道补充资本金, 优化资本结构, 偿付能力严重不足 将引发持续经营危机。

显然, 在自身积累较慢, 国家注资财力有限, 民 营资本进入管制较严格的背景下, 通过与有价值的国 际投资者合作引入外资的增资方式, 又涉及诸多更复 杂的问题。在现有资本市场的管制和保险监管背景下, 各种进入保险业的资金来源渠道并不通畅, 只能少数 公司能够通过上市来优化股权结构和扩充资本金, 多 数保险公司资本结构不良的问题还将继续存在。而且, 进入保险业的资金渠道受阻, 不仅导致资本规模偏小, 资本结构单一, 还影响承保能力和投资收益, 还可能 对投资规模造成约束, 限制了偿付能力的同步增长, 业务拓展必然受限。

\section{6. 目标迫求错位, 经营管理粗放}

保险公司在 “三轻三重” (重展业轻理赔, 重数 量轻质量, 重规模轻效益) 数量规模经营管理理念指 导下, 形成了 “三高一低” (高投入、高消耗、高增 长和低效益) 的粗放增长发展模式, 保险公司产能水 平普遍较低, 经营管理落后, 追求目标错位等问题, 
已成损害经营绩效和持续健康发展的一大顽疾。具体 来说, 公司内控能力差, 基层公司造假报表和假赔案, 顶保费或增费用等虚假现象泛滥。一些公司至今在测 算赔付率时仍采用简单赔付率, 未引进历年制赔付率、 满期赔付率等较为科学的测算指标, 未决赔款的估算 采用下达指标的简单方式, 可大可小, 偏离实际, 造 成核算不准。在用人制度上, 国有公司和部分股份制 公司基本沿用了机关工作人员的管理办法, 采取区域 行政管理, 论资排辈现象严重, 人才短缺与浪费并存, 组织机构庞大, 管理信息传递不畅和不对称, 分支机 构不能更好地反映和体现总公司法人的经营意志, 出 现管理者与经营者甚至员工行为目标不一致, 总公司 与分支公司间经营目标错位, 导致过高的经营成本吸 收了大量的营业利润, 也加重了消费者负担, 由此凸 显了高保障、高赔付和低价格的境外保险的吸引力, 加重了地下保单的蔓延。

实质上, 保险公司 “三轻三重”与 “三高一低” 的粗放经营和效率低下, 是保险公司经营管理不科学 和不合理导致的, 是委托一代理关系中经营管理不落 实与公司治理失效的表现, 甚至出现公司治理不规范, 或者治理形同虚设, 内部人控制与关联交易严重, 缺 乏股东利益的有效制衡, 没有形成激励相容的经营管 理和有效的公司治理机制。尤其是大保险公司在 “老 三险”的展业和续保上存在比较大的规模效应和品牌 优势, 销售网络早已遍布全国各地, 新生保险公司在 这些险种上没有竞争优势, 只能在大保险公司后面 “跟风”, 导致供方市场的价格竞争十分激烈, 但买 方市场缺乏保险知识, 只能被动地接受保险公司提供 的险种, 对具体险种需求的倾向性不强。相反, 新开 的保险公司都把能够迅速带来大量现金流的产品奉 为抢占市场份额的法宝, 以至于单一产品在总业务中 占到 $60 \%$ 以上, 有的新公司甚至高达 $80 \%$ 以上, 业务 拓展主要是通过价格竞争产生的数量规模来实现的, 长期 “三轻三重” 形成的 “三高一低” 的粗放经营, 已经没有动力改善其法人治理结构, 不能完全按照现 代企业制度建立运行机制, 没有建立以效益为核心、 以偿付能力为基础的管理体制, 业务增长更多依靠设 机构、铺推子, 依靠简单的费率和手续费竞争占领市 场, 对保险资源进行掠夺性开发。

\section{7. 险种创新滞后, 业务结构失衡}

我国保险市场潜在需求巨大与有效需求不足并 存, 竞争过度与开发不足并存, 整个行业集中于传统 而狭窄的经营领域, 产品集中在传统型规模效益好的 险种上, 社会经济发展和人们生活需要密切相关的险 种却供给缺位, 并呈负增长, 产品结构严重失衡, 与
我国经济增长和国民财富增长形成的风险需求严重 不对称, 保险无效供给过剩与有效供给不足的结构性 矛盾突出。而且, 保险公司之间的险种差异化程度很 低, 相似率极高, 同构现象严重, 竞争处于一个低水 平层面, 难以形成有特色的竞争优势, 降价让利就成 为重要竞争手段, 导致了寿险与财险结构比例失衡。 整个保险市场出现老产品虚假饱和, 险种结构在供需 上的错位, 导致结构失衡, 无效供给过剩, 有效供给 不足。

险种创新滞后, 业务结构失衡的根源, 主要是由 于保险公司的产品创新能力和动力不足, 市场需求的 前期调查做得不充分, 市场定位不准, 在开发产品时 大都没有考虑营销的特点, 经常出现开发出来的产品 与实际需求和营销环节脱节, 缺乏适应营销特点和要 求的产品, 真正适销对路的险种较少。仅从寿险市场 来看, 产品结构长期失衡, 导致寿险市场上以传统储 蓄投资型产品对非保险型储蓄和投资类产品的替代, 保险型储蓄投资类产品的风行, 资金频繁转换和相互 挤兄现象严重冲击了非保险的证券投资和银行储蓄 业务, 没有充分发挥人身保险业在风险保障管理和长 期资产负债匹配管理方面的核心优势。甚至在东南沿 海经济发达地区, 寿险业务甚至占到 $2 / 3$ 以上, 围绕 人民生产与生活需要的产品不多, 满足经济社会发展 和人民群众的需要的产品创新非常缓慢。而且, 如果 险种间不能形成匹配, 不能通过组合效应化解承保业 务的系统性风险, 行业成长风险将逐渐累积, 不仅会 导致保险业增长路径不良, 出现增长与发展背离的现 象, 还会引发保险业在快速成长过程中的系统性风险, 最终会阻碍保险发展。

\section{4. 中国保险业的挑战与突破方向}

当研究区域上的数据不完整时, 有两种传统的方 法, 或许能补齐数据, **在当前国内外错综复杂的形 势下, 在新的银行保险合并监管下, 准确把握现代保 险产业结构与增长路径的风险演化特征和趋势是至 关重要的。特别是在经济转轨和社会转型时期, 更应 深入研究如何使保险业适应和促进经济社会发展, 促 进城乡融合发展, 积极参与精准扶贫, 推动乡村振兴, 增进人民福祉, 探索适合中国国情的保险业发展之路, 深入研究保险结构的决定机制、调节机制和优化机制, 提出保险结构优化的判断标准和评价指标, 探索保险 结构优化的发展模式, 为主动调整和优化保险结构提 供发展理论依据。 
4.1. 市场格局失衡、智能信息芝术下市场博弃加剧、 结构不优加剧了市场复杂化

首先, 成长性市场格局失衡, 传统保险经营观念

被颠覆。从全球保险趋势来看, 发达国家目前保险业 发展非常成熟, 市场已趋饱和, 竞争十分激烈, 相对 有限的保险资源, 保险产业资源过剩。新兴市场化国 家保险资源率开发度很低, 保险产业资源不足且利用 效率低。世界保险业这种不平衡发展格局加剧了以结 构优化升级为核心的保险产业资源并购和保险资源 争夺。世界保险资源与保险产业资源的跨国流动及其 形成的世界保险关系会更加复杂, 保险业竞争力弱势 的发展中国家的保险资源和保险产业资源会进一步 流失, 金融主权与金融安全受到冲击。

尽管世界保险资源分布不均衡, 世界保险发展不 平衡, 但以风险管理与保险技术、组织制度、经营理 念和文化意识等的创新, 推动了世界保险业以结构优 化升级为核心的产业并购与融合, 保险经济活动价值 链的结构也复杂起来, 面对区块链数字技术、量子通 讯和无人驾驶等智能金融保险技术的冲击, 传统保险 服务业的两个微观端口（核保+核赔）与两个宏观轮 子 (承保业务+投资业务) 已经发生彻底变化, 长期 依靠投资业务利润补贴承保业务亏损的传统保险经 营观念已逐渐被颠覆。

其次, 智能信息技术下市场博恋加剧, 增长 (做 大) 与发展 (做强) 不协调。面对智能金融保险技术 的冲击, 许多以前没有或不被重视的风险不断涌现, 比如, 网络安全和网络犯罪风险、IT/系统和技术差 距风险、定价和产品线利润风险、索赔失控频率或严 重程度风险、客户互助平台与互助保险转化的风险、 新兴业务承保竞争风险等新变化把握得不好, 将造成 整个行业在战略方向和机会错失的风险, 发展中存在 的以“偏离保障体质”和“颠覆性技术冲击”趋势把握 不准的风险, 正在成为保险业做大做强和持续健康发 展的障碍, 难以保证保险业增长（做大）与发展（做 强) 同步, 还做不到把保障社会经济发展和人民生活 质量提高放在第一位, 现代保险服务业离人民美好生 活需要和国家发展战略要求还比较远。

另外, 总量与结构矛盾制约保险保障功能和服务 效率。为顺应产业价值链的结构变化, 产业组织结构 也发生了巨变,一个金融保险资源与金融保险技术共 享的业务融合的国际保险大市场正在逐渐形成, 世界 保险业已开始进入了垄断竞争格局的快速发展时期。 这是顺应全球经济金融化和金融自由化, 以及全球保 险创新以及竞争态势的不平衡, 以保险产业资源的重 组为核心所做出的战略性结构调整。但是, 在中国保
险总量快速增长的同时, 保险结构却没有得到同步优 化, 长期非均衡粗放发展模式, 导致的保险资源开发 利用率较低, 保险产业资源使用效率不高, 保险与社 会经济发展和人民生活需要不相适应, 与党中央明确 要求 “加快发展现代保险服务业, 为经济转轨和社会 转型的国家发展战略服务”还不相适应, 与全球经济 金融自由化下的开放新形势还不相适应, 发展中积累 的一系列问题严重地制约了保险保障功能的发挥和 现代保险服务效率的提高。

\section{2. 保护和激励创新, 引导行业服务升级, 与强化监 管和防范创新风险并举}

首先, 在挑战面前, 中国保险业应准确把握保险 业发展演化的特征与趋势, 促进微观保险主体风险管 理与保险的技术创新、组织制度创新和文化意识创新, 坚守保险保障本质, 以创新推动产业价值链的突破, 形成新的业务发展空间和利润增长点。

其次, 事实上, 在人口与科技的演进中, 在随机 理想与博亦现实的冲突中, 在中国巨大的成长性市场, 只要保护和激励创新, 引导保险行业服务升级, 在保 障中助力社会资源的有效配置方面发力突破, 全面推 动产业增长路径优化和竞争力跃升, 在适应保险国际 化趋势中提升产业综合实力。同时, 强化行业偿付能 力监管和防范创新风险, 中国保险服务业可以实现新 的突破和全面升级。

\section{参考文献}

[1] 刘茂山. 保险经济学.中国经济出版社, 1989,P1-182

[2] 林宝清. 保险发展模式论. 中国金融出版社, 1993,P1-161

[3] 刘茂山. 保险经济学(修订版). 南大学出版社, 2000, P1-133

[4] Skipper. 国际风险与保险一环境管理分析. 机械工业 出版社, 1999, P1-213

[5] Klein R W. Structural Change and Regulation Response in the Insurance Industry. NAIC General Information. June 1995

[6] 郑功成. 全面深化改革与中国保险业的发展: 大机遇 大挑战大发展. 保险研究, 2015, (1)：3-7

[7] 宋平凡, 祁毓, 徐娟. 供给侧下保险业发展模式检验: 经济驱动还是风险驱动——基于面板 VAR 模型的实 证研究. 保险研究, 2017, (10): 16-28

[8] 王绪瑾. 把握中国保险业发展的战略机遇期. 中国保 险, 2017(12): 6-10

[9] 张忠平, 胡颖, 余群芳, 徐展, 叶晓凌. 商业保险服务 供给侧改革研究一一以商业寿险公司参与社会治理为 例. 2016 年度浙江保险科研成果选编, 2017.9, P6 